\section{AB1249 AN ANALYSIS OF INPATIENT REFERRALS TO RHEUMATOLOGY IN AN IRISH TERTIARY REFERRAL HOSPITAL}

K. Murray, N. Rutledge, Q. Shah, D.J. Veale. Saint Vincent's University Hospital, Dublin 4, Ireland

Background: Reviewing patients under other services is an important part of the service we deliver in our hospital's rheumatology department.

Objectives: In order to improve quality of the inpatient consult service and relevance of teaching delivered to rheumatology trainees, we wanted to examine the nature of referrals to our service.

Methods: All available consults ( $n=81$ ) were reviewed. The age, gender, urgency and referral source were recorded. The most likely reason for referral as decided by our specialist registrar (research fellow) were determined.

Results: $49 \%$ of patients were 70 years of age or older. $30 \%$ of patients were $70-$ 79 years old. $68 \%$ were female. There was a wide range of referrals, $21 \%$ were vasculitides (including polymyalgia and giant cell arteritis), $20 \%$ inflammatory arthritides, $19 \%$ crystal arthropathies, $16 \%$ connective tissue disease, $14 \%$ osteoarthritis, $3 \%$ septic arthritis, $3 \%$ fibromyalgia, $3 \%$ pyrexia of unknown origin, $1 \%$ sarcoid, $1 \%$ antphospholipid syndrome and $1 \%$ osteoporosis.

$59 \%$ of consults came from general medical teams, $14 \%$ from acute medicine, $14 \%$ from surgery, $3 \%$ from psychiatry and $11 \%$ from other inpatient services (including haematology, oncology etc).

$36 \%$ of consults were considered urgent (to be seen within 24 hours) by the referring team, $64 \%$ were routine (to be seen within 48 hours).

Conclusions: Almost half of referrals were over 70 years of age. Most referrals came from medical teams. The majority of consults were women and referred due to a vasculitis, inflammatory arthritis or connective tissue disease. $3 \%$ were septic arthritis. Our trainee teaching will now focus primarily on these topics.

$3 \%$ of referrals were for fibromyalgia, which could perhaps be managed on an outpatient basis. This may improve utilisation of limited inpatient hospital resources.

Disclosure of Interest: None declared

DOI: 10.1136/annrheumdis-2018-eular.2233

\section{AB1250 VACCINATION AWARENESS AND UPTAKE IN INFLAMMATORY ARTHRITIS PATIENTS}

K. Murray, A. O'Rourke, C. Low, F. Young, E. Feeney, D.J. Veale. Saint Vincent's University Hospital, Dublin 4, Ireland

Background: Inflammatory arthritides (IA) increase infection risk. The Centre for Disease Control and Prevention recommends influenza vaccination for all adults and pneumococcal vaccine for $>65$ years old and under 64 years receiving certain immunosuppressive therapies, including TNF inhibitors.

Objectives: We examined patients' knowledge, uptake and attitudes to influenza and pneumococcal vaccination and opportunities to increase vaccination rates in our IA clinic.

Methods: Patients attending the IA Clinic completed an anonymous 23 question worksheet recording demographic details, medical history, medications, knowledge about vaccinations, vaccination status, reasons for non-vaccination and availability and willingness to use smartphone for healthcare records.

Results: 329 patients completed the survey. Respondents were predominantly female $(78 \%)$. $69 \%$ were $>50$ years old. $82 \%$ had completed secondary education. $59 \%$ of patients had rheumatoid arthritis, $11 \%$ had psoriatic arthritis and $30 \%$ other conditions. $29 \%$ of patients were taking a biological DMARD, $27 \%$ using methotrexate and $19 \%$ oral steroids.

$52 \%$ knew some rheumatological conditions increase infection risk. 54\% knew some rheumatological medications can increase infection risk.

$66 \%$ knew influenza vaccination was recommended, most commonly via their general physician (GP) (70\%). 50\% of patients were up to date with their 'flu' vaccination, mainly $(75 \%)$ via their GP. Reasons for non-vaccination included lack of awareness $(45 \%)$ and fear of side effects $(25 \%)$.

$29 \%$ knew pneumococcal vaccination may be indicated, $78 \%$ of whom were informed by their GP. 33\% of patients were up to date with their pneumococcal vaccine. $80 \%$ cited lack of awareness for non-vaccination.

$70 \%$ of patients had smart phone access. $74 \%$ of these were willing to use this for their healthcare record and reminders re vaccination.

Conclusions: These data show low awareness amongst IA patients of the risk of immunosuppression associated with their disease and treatments and the need for regular vaccinations. Mobile technology may help increase vaccination rates.

Disclosure of Interest: None declared

DOI: 10.1136/annrheumdis-2018-eular.2231

\section{$\mathrm{AB} 1251$ \\ QUALITY OF INPATIENT REFERRALS TO RHEUMATOLOGY IN AN IRISH TERTIARY REFERRAL HOSPITAL}

K. Murray, N. Rutledge, Q. Shah, D.J. Veale. Saint Vincent's University Hospital, Dublin 4, Ireland

Background: A previous audit of inpatient referrals to our service found $21 \%$ were vasculitides, $20 \%$ inflammatory arthritides, 19\% crystal arthropathies, and $16 \%$ connective tissue disease. It was felt that many of these referrals lacked appropriate investigations (such as inflammatory markers) prior to rheumatology review.

Objectives: Prior to transitioning from handwritten to electronic consults, we wanted to examine the data given in inpatient referrals to our service.

Methods: All available consults $(n=81)$ were reviewed. We assessed whether the age/date of birth, gender, location, duration of symptoms, medications, clinical examination findings, reason for consult, urgency and suspected diagnosis had been written on the consult request form. We examined what investigations were detailed (any blood result, C Reactive Protein (CRP) value and any imaging result) and what referrer details were given (name, contact details, consultant responsible).

Results: In $99 \%$ of cases, patients age or date of birth was given by the referring team. $84 \%$ detailed gender. $78 \%$ contained ward. $68 \%$ contained bed number. $56 \%$ listed urgency.

$96 \%$ indicated reason for consult. $30 \%$ listed duration of symptoms. $21 \%$ detailed whether patient known to rheumatology service. $57 \%$ gave suspected diagnosis. $33 \%$ gave medications. $42 \%$ detailed clinical examination findings. $41 \%$ reported any blood test. $27 \%$ gave a CRP. $44 \%$ detailed imaging findings.

$49 \%$ contained referrer name. $80 \%$ had referrer contact details. $70 \%$ gave referring consultant.

Conclusions: Overall, it was felt many of the inpatient referrals to our service lacked potentially important details. Less than half of consult requests included duration of symptoms, medications, examination findings, blood test results or referrer name.

We will soon be transitioning to an electronic referral system and all of these data points must be entered prior to submission of the consult. Hopefully, this will improve the quality of care we deliver to our patients.

Disclosure of Interest: None declared

DOI: 10.1136/annrheumdis-2018-eular.2234

\section{AB1252 PREVALENCE OF ANALGESIC USAGE IN PATIENTS WITH RHEUMATOID ARTHRITIS AND RELATIONSHIP WITH DISEASE ACTIVITY}

L. Villarreal ${ }^{1}$, D. Buitrago-Garcia ${ }^{2}$, M. Cabrera ${ }^{1}$, P. Santos-Moreno ${ }^{3} .{ }^{1}$ Health Services; ${ }^{2}$ Epidemiology; ${ }^{3}$ Rheumatology, Biomab, Center For Rheumatoid Arthritis, Bogota, Bogota, Colombia

Background: Rheumatoid arthritis (RA) is a systemic, autoimmune disease in which chronic pain is a persistent symptom, ${ }^{1}$ aditionally pain management remains as a serious public health issue. Pain is often disabling and can reduce the quality of life of a patient $\left({ }^{2}\right.$

Objectives: To describe prevalence of analgesic usage in patients with rheumatoid arthritis and relationship with disease activity.

Methods: We collected data from the medical charts in a specialised RA centre conducted during 2017, we performed a descriptive analysis, we collected sociodemographic information, DAS28, and the prevalence of prescription of analgesic medications divided in three groups non opioid analgesics, opioid analgesics and NSAIDS. We calculated means, and standard deviations for continuous variables and categorical variables were presented as rates. We estimated the prevalence of comorbidities and evaluate independent associations calculating prevalence ratios.

Results: We included data from 6700 patients, $80 \%$ were women and $20 \%$ were men. Mean age was 59 years $\pm 13,47 \%$ of all patients were between 60 and 80 years; The prevalence of use pain medications was $63.41 \%$. Most of patients received non opioid analgesics $52 \%$ (paracetamol or dipyrone) followed by opioids $23 \%$ (codein or tramadol), $10 \%$ of patients had pain medication combination of non opioids plus opiods. See table 1. The prevalence of pain medications usage was associated with sex but not with disease activity see table 2 . 
Abstract AB1252 - Table 1. Characteristics of patients with RA and comorbidities

\begin{tabular}{lcc}
\hline Pain medication & $\mathbf{n}$ & $\%$ \\
\hline Non-opioids & 2234 & 52 \\
Opioids & 990 & 23 \\
NSAID & 67 & 2 \\
COMBINATIONS & & \\
Non opioids & 430 & 10 \\
+ Opioids & & \\
Non opioids & 309 & 7 \\
+NSAID & & \\
Opioids+NSAID & 209 & 5 \\
All & 70 & 2 \\
\hline
\end{tabular}

Conclusions: Rheumatoid arthritis is a pain associated condition; two thirds of patients are using of pain medications mainly women; the most prescribed medication was paracetamol or opioids, coinciding with other studies. ${ }^{2}$ This descriptive study is useful for further studies to develop in Latin America.

\section{REFERENCES:}

[1] Parker JC, Frank RG, Beck NC, Smarr KL, Buescher KL, Phillips LR, et al. Pain management in rheumatoid arthritis patients. Arthritis \& Rheumatism. 1988;31(5):593-601.

[2] Samison LH, Randriatsarafara FM, Ralandison S. Joint pain epidemiology and analgesic usage in Madagascar. The Pan African medical journal. $2017 ; 26: 77$.

Disclosure of Interest: None declared

DOI: 10.1136/annrheumdis-2018-eular.7201

\section{AB1253 ANALGESIC DRUGS AND RISK OF ISCHAEMIC STROKE IN PATIENTS WITH OSTHEOARTRITIS: A REAL WORLD DATA CASE-CONTROL STUDY}

A. Gomez-Lumbreras ${ }^{1}$, R. Vives ${ }^{2,3}$, M. Giner-Soriano ${ }^{1,3,4}$, H. Pera ${ }^{1}$, M. Fradera ${ }^{2}$, J. R. Marsal ${ }^{5}$, R. Morros ${ }^{1,3,4} .{ }^{1}$ Medicines Research Unit, Institut Universitari d'Investigació en Atenció Primària (IDIAPJGol), Barcelona; ${ }^{2}$ Institut d'Investigació i Innovació Parc Taulí, Corporació Sanitària Parc Taulí, Sabadell; ${ }^{3}$ Universitat Autònoma de Barcelona: ${ }^{4}$ Institut Català de la Salut, Barcelona; ${ }^{5}$ Unitat de Suport a la Recerca, Institut Universitari d'Investigació en Atenció Primària (IDIAPJGol), Lleida, Spain

Background: Pharmacological treatment of ostheoartritis (OA) usually include analgesics, non-steroidal anti-inflammatory drugs (NSAID) and symptomatic slow-acting drugs in OA (SYSADOA). The association between these groups of drugs and the risk of ischaemic stroke has not been properly addressed.

Objectives: To analyse the risk of stroke in patients using analgesics, NSAID and SYSADOA drugs.

Methods: We used a population-based patient hospital registry to identify all patients with a first-ever stroke discharge diagnosis between 2009-2015. Cases were matched to controls obtained from the Information System for Research in Primary Care (SIDIAP) database. Information on drug exposure was obtained from invoice data from pharmacies. Crude and adjusted odds ratios $\left(\mathrm{OR}, \mathrm{OR}_{\mathrm{adj}}\right)$ and their $95 \%$ confidence interval $(95 \% \mathrm{Cl})$ were calculated using multivariate models of conditional logistic regression for the next pharmacological groups and individual agents of each group: acetic acid derivatives, oxicams, propionic acid and derivatives, coxibs, SYSADOA and analgesics (opiods, metamizole and paracetamol). A cardiovascular risk score was calculated for each subject based on comorbidities.

Results: 12616 cases were matched to 125264 controls by gender, age and geographic area. Among cases, 43\% were women. The mean age was 72.6 (IQR 65-82) years and more cases were classified as high cardiovascular risk patients $(n=2,511,19.9 \%)$ than controls $(n=12,467,10.0 \%)$. Mortality in the following year after the index date was higher for cases $(n=2,633,20.9 \%)$ than for controls $(n=8,168,6.5 \%)$. A higher percentage of cases had a previous diagnostic of ischaemic heart disease, $13.8 \%(n=1,745)$ vs $7.7 \%(n=9,656)$ of the controls. OA diagnosis was present in $2823(22.4 \%)$ cases and in 29098 (23.2\%) controls. Paracetamol was the most used drug $(n=106,515,77.3 \%)$ followed by ibuprofen $(\mathrm{n}=84,790,61.5 \%)$.

Current users of acetic acid derivatives showed an increased risk of stroke $\left[\mathrm{OR}_{\mathrm{adj}}\right.$. $(95 \% \mathrm{Cl}) 1.10(1.01-1.19)]$, so did diclofenac [OR $\left.{ }_{\mathrm{adj}} 1.14(1.04-1.25)\right]$. Among the propionic acid derivatives, current users showed an increased risk $\left[\mathrm{OR}_{\mathrm{adj}} 1.24\right.$ $(1.27-1.32)]$, dexketoprofen showed the highest risk $\left[\mathrm{OR}_{\mathrm{adj}} 1.42(1.25-1.60)\right]$ and naproxen the lowest $\left[\mathrm{OR}_{\text {adj }} 1.18(1.02-1.37)\right]$. The SYSADOA group did not show any increased risk for any type of exposure, with a decreased risk of $17 \%$ $\left[O R_{\text {adj }} 0.83(0.77-0.91)\right]$ for lifetime glucosamine exposure and a $22 \%\left[\mathrm{OR}_{\mathrm{adj}} 0.84\right.$ $(0.78-0.90)]$ for chondroitin sulfate. Analgesics were the most consumed drugs, and cases were more exposed to all subgroups of analgesics than controls. While the non-adjusted OR showed an increased risk of stroke for lifetime exposure for all agents in this group, this association was not observed with the adjusted $\mathrm{OR}_{\mathrm{ad}}$ for fentanyl, neither buprenorphine, but it showed a risk for current users of meta-

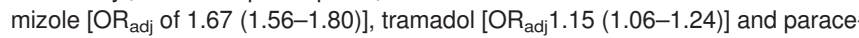
tamol [OR $\left.{ }_{\text {adj }} 1.43(1.37-1.51)\right]$

Conclusions: Current exposure to NSAIDs, tramadol, metamizole and paraceta$\mathrm{mol}$ is a risk factor for ischaemic stroke. Exposure to chondroitin sulphate and glucosamine are associated with a lower risk of ischaemic stroke.

Disclosure of Interest: None declared

DOI: 10.1136/annrheumdis-2018-eular.1428

\section{AB1254 IMPROVING RHEUMATOLOGIC CARE AND EDUCATION IN THE REPUBLIC OF MACEDONIA: A MODEL FOR PROMOTING RHEUMATOLOGIC EDUCATION IN A DEVELOPING COUNTRY}

V. Ognenovski ${ }^{1}$, M. Arsovska-Nalbanti ${ }^{2} .{ }^{1}$ Division Rheumatology, University of Michigan, Ann Arbor, USA; ${ }^{2}$ Division Rheumatology, Clinical Center Dr. Trifun Panovski, Bitola, Macedonia, The Former Yugoslav Republic of Ireland

Background: : In 2011 ILAR supported a pilot project in training a rheumatologist in an underserved area in Macedonia. The pilot took place in the clinical centre of Bitola. Previously, rheumatologic care was provided by visiting rheumatologists from the rheumatology clinic in the capital city.

Objectives: The primary goal of this project was to pilot a model in rheumatologic training and improve rheumatologic care in an underserved area in Macedonia.

Methods: An internist from the clinical centre in Bitola was enrolled in a two-yea training by the Rheumatology clinic at Ss Cyril and Methodius University in Macedonia, and the rheumatology division at the University of Michigan. Pre intervention metrics of quality of care as measured by access, standard therapy, and DAS 28 scores were compared with post intervention metrics.

Results: The primary goal of the project enabled training of a rheumatologist. A local internist completed her training in rheumatology (2014), and established a rheumatology clinic within the clinical centre in the city of Bitola in 2014, providing daily access to patients with rheumatic conditions in a region with a population of 300 000. Patient access changed from 120 visits/month to 800 visits/month. The service provided consultations to hospitalised patients.

The secondary endpoints: quality of care as measured by standard therapy for rheumatoid arthritis and DAS-28 scores are as shown on table 1.

\begin{tabular}{|c|c|c|c|}
\hline $\begin{array}{l}\text { Rheumatoid Arthritis } \\
\text { patients }\end{array}$ & $\begin{array}{l}\text { Pre-intervention } 2011 \\
\quad(n=115)\end{array}$ & $\begin{array}{c}\text { Post-intervention } 2017 \\
\quad(\mathrm{n}=86)\end{array}$ & $\begin{array}{c}\text { Statistical } \\
\text { Significance }\end{array}$ \\
\hline $\begin{array}{l}\text { Patients taking } \\
\text { methotrexate }\end{array}$ & $44 \%$ & $53 \%$ & \\
\hline Methotrexate dose & $11.5 \mathrm{mg}(10-15 \mathrm{mg})$ & $13.9 \mathrm{mg}(10-25 \mathrm{mg})$ & $p<0.00001$ \\
\hline Combination therapy* & $39 \%$ & $38.5 \%$ & NS \\
\hline Dual therapy* & $31 \%$ & $35 \%$ & NS \\
\hline Triple therapy* & $3.5 \%$ & $5 \%$ & NS \\
\hline DAS-28 average & 4.8 & 4.41 & NS \\
\hline
\end{tabular}

MTX=methotrexate; *methotrexate, sulfasalazine, leflunomide, antimalarial (chloroquine, hydroxychloroquine)

Post intervention, more patients were taking methotrexate and at higher doses Despite this trend, its average dose was less than $50 \%$ of its maximal dose (25 mg/week) commonly used in standard practice. The frequency of combination therapy remained unchanged. Likewise, no significant change in the DAS-28 scored was observed.

Conclusions: Prior to launching the pilot, the rheumatologic care in this region was provided by visiting rheumatologists from the university clinic in the capital city. Initial assessment pointed to several obstacles: poor access and substan dard therapy that likely contributed to the prevalence of high disease activities. Our pilot succeeded in training a rheumatologist, thus reaching our primary goal of improving local access to rheumatic care. The secondary goals of improving the quality of care as measured by the DAS-28, standard of therapy for rheumatoid arthritis- reflected by appropriate use of DMARDS (use of methotrexate, combination therapy) showed a modest improvement While higher doses of methotrexate were use, combination therapy and better control of rheumatoid arthritis (DAS-28) remained unchanged, thus posing a challenge for ongoing need and future intervention goals.

\section{REFERENCE}

[1] Ognenovski, VM, Arsovska- Nalbanti, M, Chichikj D, Calovski, J. Improving care and education in the Republic of Macedonia: model for rheumatologic 